\title{
Characterization of a shorter recombinant polypeptide chain of bone morphogenetic protein 2 on osteoblast behaviour
}

\author{
Yufeng Zhang ${ }^{1,2^{*}}$, Yang Shuang ${ }^{1}$, Hang Fu' ${ }^{5}$, Wei Zhou ${ }^{5}$, Li Qian ${ }^{5}$, Jing Dai ${ }^{1}$ and Richard J. Miron ${ }^{1,3,4}$
}

\begin{abstract}
Background: Recombinant bone morphogenetic protein two (rhBMP2) has been utilised for a variety of clinical applications in orthopaedic surgery and dental procedures. Despite its widespread use, concerns have been raised regarding its short half-life and transient bioactivity in vivo. Recent investigation aimed at developing rhBMP2 synthesized from a shorter polypeptide chain (108 amino acids) has been undertaken.

Methods: The osteopromotive properties of BMP2 were investigated on cell behaviour. Five concentrations of rhBMP2_108 including 10, 50, 100, 200 and $500 \mathrm{ng} / \mathrm{ml}$ were compared to a commercially available rhBMP2 (100 ng/ml). Each of the working concentrations of rhBMP2_108 were investigated on MC3T3-E1 osteoblasts for their ability to induce osteoblast recruitment, proliferation and differentiation as assessed by alkaline phosphatase (ALP) staining, alizarin red staining, and real-time PCR for genes encoding ALP, osteocalcin (OCN), collagen-1 (COL-1) and Runx2.

Results: The results demonstrate that all concentrations of rhBMP2_108 significantly improved cell recruitment and proliferation of osteoblasts at 5 days post seeding. Furthermore, rhBMP2_108 had the most pronounced effects on osteoblast differentiation. It was found that rhBMP2_108 had over a four fold significant increase in ALP activity at seven and 14 days post-seeding and the concentrations ranging from 50 to $200 \mathrm{ng} / \mathrm{ml}$ demonstrated the most pronounced effects. Analysis of real-time PCR for genes encoding ALP, OCN, COL-1 and Runx2 further confirmed dose-dependant increases at 14 days post-seeding. Furthermore, alizarin red staining demonstrated a concentration dependant increase in staining at 14 days.
\end{abstract}

Conclusion: The results from the present study demonstrate that this shorter polypeptide chain of rhBMP2_108 is equally as bioactive as commercially available rhBMP2 for the recruitment of progenitor cells by facilitating their differentiation towards the osteoblast lineage. Future in vivo study are necessary to investigate its bioactivity.

Keywords: BMP2, Osteoinductive, Osteoinduction, Osteoblast differentiation, Guided bone regeneration

\section{Background}

The use of growth factors and biomaterials with bone inducing properties has played a pivotal role in treatment options for patients suffering from a variety of bone defects caused by either fracture or disease [1-3]. Osteoporosis, a disease characterized by low mineral

\footnotetext{
*Correspondence: zyf@whu.edu.cn

${ }^{1}$ The State Key Laboratory Breeding Base of Basic Science of Stomatology (Hubei-MOST) \& Key Laboratory of Oral Biomedicine Ministry of Education, School \& Hospital of Stomatology, Wuhan University, 237 Luoyu Road, Wuhan 430079, People's Republic of China

${ }^{2}$ Department of Oral Implantology, School of Stomatology, Wuhan University, Wuhan 430079, China

Full list of author information is available at the end of the article
}

density and subsequent fragility [4] has now reached an estimated 200 million people worldwide with $80 \%$ being post-menopausal women [5-7]. The significant increase in bone metabolic diseases in combination with traumatic injuries caused by sports accidents, motor vehicle accidents and other related fractures necessitates bone inducing agents capable of speeding up bone regeneration often in compromised scenarios such as osteoporotic related fractures [8-11].

One growth factor that has been widely used with FDA approval is that of bone morphogenetic proteins (BMPs) [12-14]. BMPs were initially extracted from demineralized bone matrix and it was revealed that these 
low-molecular weight proteins demonstrated the ability to form ectopic bone in extra-skeletal sites in animals $[15,16]$. Since then, BMPs have been capable of regenerating a multitude of osseous defects and have been shown to improve cell recruitment, proliferation and differentiation of mesenchymal cells, and speeding up their differentiation towards bone forming osteoblasts [17]. Despite the clinical advantages of recombinant proteins, concerns have been raised regarding their transient bioactivity, protein instability, fast dissolution rates and short half lives [18]. For these reasons, the use of rhBMPs are typically administered in high supra-physiological doses that bear the risk of potential side effects associated with their use [19]. Furthermore, other factors that could lead to a reduced in vivo bioactivity include the role of antagonists and their specificity for different BMPs (noggin, chordin, dan), the role of the host organism for expression (E.coli vs. $\mathrm{CHO}$ ) and the associated differences in glycosylation patterns that might lead to differences in bioavailability and stability [20-22].

Recently the development of a novel recombinant protein fabricated from a shorter polypeptide chain of BMP2 has been undertaken with the aim of improving protein stability in vivo. This shorter protein chain is hypothesized to facilitate protein folding, thus potentially improving the bioactivity of rhBMP2 by increasing the half-life of the protein [23]. However, prior to animal testing, a full characterization of this shorter amino acid sequence was investigated on cell behaviour in vitro. MC3T3-E1 pre-osteoblasts were investigated for their response to five different concentrations of rhBMP2_108 including 10, 50, 100, 200 and $500 \mathrm{ng} / \mathrm{ml}$ and compared to control commercially available rhBMP2 at a concentration of $100 \mathrm{ng} / \mathrm{ml}$ (R\&D systems). rhBMP2_108 was tested for its ability to induce cell recruitment, cell proliferation, alkaline phosphatase activity, alizarin red staining as well as mRNA levels for genes encoding alkaline phosphatase, osteocalcin, collagen one and Runx2 as assessed by real-time PCR.

\section{Methods}

rhBMP2_108 amino acid sequence

rhBMP2_108 was kindly provided by Jiuyuan biotech company (Hangzhou, China). The shortened amino acid sequence was fabricated as follows: MKKLKSSCK RHPLYVDFSDVGWNDWIVAPPGYHAFYCHGECPF PLADHLNSTNHAIVQTLVNSVNSKIPKACCVPTELSAI SMLYLDENEKVVLKNYQDMVVEGCGCR for a protein chain of 108 amino acids. The commercially available BMP2 was purchased from R\&D systems (Minneapolis, USA).

\section{Preparation of BMP2}

According to the amino acid sequence, intracellular expression of rhBMP2_108 in E. coli was constructed for bulk production of rhBMP2_108 as previously described [24]. Briefly, the sequence of BMP2 was designed according to its amino acid sequence, and then was reverse transcribed with reverse transcriptase (Gibco BRL, NY, USA) as previously described [24]. Polymerase chain reaction (PCR) was used to amplify the cDNA encoding the shortened amino acid sequence rhBMP2_108 protein. This rhBMP2_108 cDNA was then subcloned using a pRSET(A) vector (Invitrogen, UK) to yield the pRSET(A)/ rhBMP2_108 expression vector. Then, pRSET(A)/rhB MP2_108 was further utilized to transform the E. coli BL21(DE3) strain. A bioreactor was then utilized to yield high cell-density cultivation of E. coli. Briefly, transformed E. coli was cultured in a $5 \mathrm{~L}$ fermenter, with $3 \mathrm{~L}$ of the defined medium (batch culture; yeast extract $1 \mathrm{~g} / \mathrm{L}$, peptone $2 \mathrm{~g} / \mathrm{L}$ ) inoculated with the pre-culture (10\% of the batch culture volume). The cultivation was performed with stirring at $250 \mathrm{rpm}$ for $48 \mathrm{~h}$ at $30{ }^{\circ} \mathrm{C}$, including the addition of a nutrient medium (glucose $33.3 \mathrm{~g} / \mathrm{L}$, peptone $10 \mathrm{~g} / \mathrm{L}$, yeast extract $5 \mathrm{~g} / \mathrm{L}, \mathrm{MgSO}_{4} 1 \mathrm{~g} / \mathrm{L}, \mathrm{FeSO}_{4} 8.0 \mathrm{~g} / \mathrm{L}, \mathrm{CaCl}_{2} 0.048 \mathrm{~g} / \mathrm{L}$, $\left.\mathrm{ZnSO}_{4} 0.0176 \mathrm{~g} / \mathrm{L}, \mathrm{CuSO}_{4} 0.008 \mathrm{~g} / \mathrm{L}\right)$.

The cultured biomass was then harvested by crushing twice the cells in a French press and thereafter centrifuged. The pellet was resuspended at $25 \mathrm{mg}$ wet weight $/ \mathrm{ml}$ in a suspension buffer $(20 \mathrm{mMTris}-\mathrm{HCl}[\mathrm{pH} 8.5]$, 0.5 mMEDTA, $2 \%[\mathrm{v} / \mathrm{v}]$ Triton X-100). The inclusion bodies (pellets) were resuspended in a solubilization buffer (6Mguanidine- $\mathrm{HCl}, 0.1 \mathrm{M}$ Tris- $\mathrm{HCl}[\mathrm{pH}$ 8.5],0.1 M DTT, $1 \mathrm{mM}$ EDTA) and thereafter incubated with constant stirring at room temperature overnight. Insoluble particles were then removed from the suspension by centrifugation.

A Heparin Sepharose 6 Fast Flow column was then used to purify the active rhBMP2_108 (dimer). A continuous $\mathrm{NaCl}$ gradient $(0.1-1.5 \mathrm{M})$ was used to elute the bound protein. Afterwards, a stepped $\mathrm{NaCl}$ gradient $(0.15 \mathrm{M}, 0.3 \mathrm{M}$, and $0.5 \mathrm{M})$ was used to elute and separate the active rhBMP2_108 protein. Thereafter rhBMP2_108 powder was frozen at $-20{ }^{\circ} \mathrm{C}$. When used, $0.1 \%$ acetic acid was utilized to dissolve the BMP2 powder. Control rhBMP2 was purchased from $\mathrm{R} \& \mathrm{D}$ systems (Minneapolis, USA) derived from $\mathrm{CHO}$ cells.

\section{Two-dimensional migration assay}

MC3T3-E1 pre-osteoblast cell line was used for this study. No human or animal samples were utilized and thus no ethical consent was required. The migration assay of cells was performed with a Transwell chamber using a 24-well plate and polycarbonate filters (Transwell Costar, Corning, Acton, MA) with a pore size of $8 \mu \mathrm{m}$ as previously described [25]. 10 ${ }^{4}$ MC3T3-E1 cells in $50 \mu$ DMEM were seeded in the upper compartment. rhBMP2_108 at concentrations of $0,10,50,100,200$ and $500 \mathrm{ng} / \mathrm{ml}$ and control rhBMP2 at $100 \mathrm{ng} / \mathrm{ml}$ were seeded into the lower compartment. The cells were allowed to migrate for $24 \mathrm{~h}$ 
at $37{ }^{\circ} \mathrm{C}$ in a humidified $5 \% \mathrm{CO}_{2}$ atmosphere. The filter was then removed, cells were fixed in $4 \%$ formaldehyde for $20 \mathrm{~min}$ and washed in PBS, after washings, filters were incubated for $15 \mathrm{~min}$ at room temperature with Methylrosanilnium Chloride Solution (Wuhan Google biotechnology limited company G1014), then the filters were washed with PBS for $10 \mathrm{~min}$. Samples were examined by microscopy. Non-migrated cells on the upper side were eliminated by rinsing the filter with cold PBS and scraping with a rubber wiper. The remaining migrated cells on the lower side of the filter were counted in nine random fields per filter ( $\times 100$ magnification). All samples were performed in triplicate with 3 independent experiments performed.

\section{Proliferation assay}

To investigate the effect of rhBMP2_108 on the proliferation of MC3T3-E1, CCK-8 assay for each group was performed as previously described [26]. Briefly, cells were seeded in 96 -well plates at a density of $5 \times 10^{3}$ cells/well. At time points 1,3 and 5 days, the CCK- 8 assay was performed by adding $10 \mu \mathrm{L}$ of the CCK- 8 solution (Dojindo Molecular Technologies, Inc. Japan) to each well and incubating for $1.5 \mathrm{~h}$ according to manufacturer's protocol. The absorbance was measured at $\lambda=450 \mathrm{~nm}$ on a plate reader. Results were demonstrated as the absorbance of each experimental well minus the optical density value of blank wells. All samples were repeated in triplicate with three independent experiments.

\section{Alkaline phosphatase activity}

Alkaline phosphatase activity was analyzed colorimetrically using alkaline phosphatase assay kit (Nanjing Jiancheng Bioengineering Insitute) using a starting seeding density of 50'000 cells per 24 well dish as previously described [27, 28]. At time point of seven and 14 days, cells were washed three times with PBS and solubilized in $0.1 \%$ Triton $\mathrm{X}-100$ (buffered in $0.1 \mathrm{~mol} / \mathrm{L} \mathrm{PBS}$, $\mathrm{pH} 7.3$ ) at $4{ }^{\circ} \mathrm{C}$ for $1 \mathrm{~h}$. After sonication and centrifugation, ALP activity in the supernatant was determined colorimetrically using readings OD405/OD562. Total protein was quantified by BCA Protein Assay Kit (Thermo Fisher Scientific Inc.). The ALP activity was normalized to the total protein. Samples were run in triplicate with three independent experiments performed.

\section{Real-time PCR}

MC3T3-E1 cells were seeded at a density of $2 \times 10^{5}$ and cultured for 14 days as previously described [26, 28, 29]. The effects of rhBMP2_108 at various concentrations were investigated on four osteogenic-related gene expression including alkaline phosphatase (ALP), collagen I (COL I), runt-related transcription factor two (Runx 2) and osteocalcin (OCN). Total RNA was extracted from MC3T3-E1 cells by Trizol reagent (TriPure Isolation
Reagent, Roche Applied Science, Germany) according to the manufacturer's instructions. The concentration and quality of the total RNA samples was analyzed by Nanodrop (Thermo Fisher Scientific Inc.). Complementary DNA was synthesized from $2 \mu \mathrm{g}$ of total RNA using RevertAidTm First Strand cDNA Synthesis Kit (Fermentas) following the manufacturer's protocol. RTqPCR was performed in $20 \mu \mathrm{L}$ reactions containing $10 \mu \mathrm{l}$ SYBR Green Master Mix (Roche Applied Science, Germany), $0.6 \mu \mathrm{L}(10 \mu \mathrm{M})$ of each forward and reverse primer for each gene of interest, $2 \mu \mathrm{L}$ of cDNA template and $6.8 \mu \mathrm{L}$ water. The primer sequences (shown in Table 1) have designed specifically according to the reference. Glyceraldehyde-3-phosphate-dehydrogenase (GAPDH), a reference gene, was used as a control. The reaction was analyzed using an ABI Prism 7000 Sequence Detection System (Applied Biosystems), and the PCR amplification run for 40 cycles. To validate specific amplicon amplification without genomic DNA contamination, melting curve analysis was performed and the single apex appeared around the annealing temperature. Relative expression levels for each desired gene were normalized against the $\mathrm{Ct}$ value of GAPDH and determined by using the delta $\mathrm{Ct}$ method. All samples were determined in triplicate for three independent studies.

\section{Alizarin red quantification}

Alizarin red staining was performed to determine the presence of extracellular matrix mineralization after 14 days. MC3T3-E1 cells were seeded at a density of 50,000 cells per 24 well culture dish containing the various concentrations of rhBMP2_108. After 14 days, cells were fixed in $96 \%$ ethanol for 15 min and stained with $2 \%$ alizarin red solution in water $(\mathrm{pH} \mathrm{4.2)}$ at room temperature for $1 \mathrm{~h}$ and visualized under light microscopy. Thereafter, alizarin red quantification was dissolved using $200 \mu \mathrm{l}$ of $1 \%$ cetylpyridinium chloride (dissolved with double distilled water) at room temperature for $4 \mathrm{~h}$. Then $100 \mu \mathrm{l}$ solution was transferred to 96-well plate to text OD 560.

Table 1 Primer sequences for osteoblast differentiation markers

\begin{tabular}{ll}
\hline GAPDH F & GTGAAGGTCGGTGTGAACGG \\
\hline GAPDH R & TCCTGGAAGATGGTGATGGG \\
OPN F & GAGGAAACCAGCCAAGGTAAG \\
OPN R & AAAGCAAATCACTGCCAATCTC \\
OCN F & GAGGACCATCTITCTGCTCACT \\
OCN R & CGGAGTCTGTTCACTACCTTATTG \\
ALP F & TGTGGAATACGAACTGGATGAG \\
ALP R & ATAGTGGGAATGCTTGTGTTG \\
RUNX2 F & GTGTTCCCTACTCAGCCGTC \\
RUNX2 R & GAGGCCTCGGTCCACATTAG \\
\hline
\end{tabular}




\section{Statistical analysis}

All data analysis was performed using GraphPad Prism6.0 software. Normal distribution of sample data was assumed for the current study and therefore parametric testing was analyzed using one-way ANOVA and statistically significant values were adopted as $p<0.05$. Mean and standard error (SE) were analyzed using oneway ANOVA with a post hoc test with Tukey's analysis.

\section{Results}

\section{Effect of rhBMP2 108 on cell recruitment}

In order to investigate the effects of rhBMP2_108 on cell recruitment, a transwell chamber was utilised at five different concentrations of rhBMP2_108 (Fig. 1). It was found that after a $24 \mathrm{~h}$ period, all concentrations of rhBMP2_108 and control rhBMP2 were able to significantly increase cell recruitment of MC3T3-E1 cells when compared to control samples. Little variability between samples was observed demonstrating a strong potential for all concentrations of rhBMP2_108 to induce cell recruitment (Fig. 1).

\section{Effect of rhBMP2 on cell proliferation}

The effect of rhBMP2_108 was investigated at five concentrations and control rhBMP2 for their ability to stimulate cell proliferation in vitro (Fig. 2). It was found that MC3T3-E1 cells demonstrated very similar cell number 1 day post-seeding irrespective of cell culture media concentration of rhBMP2_108 (Fig. 2). A slight increase in cell number was observed at 3 days, however, no significant difference could be observed between the various treatment modalities (Fig. 2). By 5 days post seeding, a significant increase in cell number was observed for MC3T3-E1 cells with all concentrations of rhBMP2_108 used in this study (Fig. 2). Interestingly, no advantages could be found for higher concentrations of rhBMP2_108 when compared to their lower counterparts (Fig. 2).

\section{Effect of rhBMP2 on cell differentiation}

RhBMP2_108 was then assessed for its ability to speed up osteoblast differentiation at various concentrations (Fig. 3, Fig. 4, Fig. 5, Fig. 6). First it was found that rhBMP2_108 was able to significantly increase ALP activity at seven and 14 days post seeding for all concentrations of rhBMP2_108 (Fig. 3). Interestingly, it was observed at 7 days that ALP activity was significantly higher at rhBMP2_108 concentrations of 50, 100 and $200 \mathrm{ng} / \mathrm{ml}$ when compared to control samples (Fig. 3). At 14 days, all treatment modalities receiving rhBMP2_108 at various concentrations demonstrated a marked 16-fold increase in ALP activity when compared to control samples void of rhBMP2_108 (Fig. 3).

Then MC3T3-E1 cells were assessed for mRNA levels by real-time PCR for genes encoding ALP, OCN, COL-1 and Runx2 at various concentrations of rhBMP2_108 (Fig. 4). For gene encoding Runx2, up to a five fold increase was observed at a concentration of $500 \mathrm{ng} / \mathrm{ml}$ when compared to control samples with a significant increase at 100 and $200 \mathrm{ng} / \mathrm{ml}$ compared to lower concentrations (Fig. 4a). Similarly, COL-1 also demonstrated concentration dependent increase in gene expression (Fig. 4b). Here however, only up to a two fold increase was observed relative to control samples (Fig. 4b). It was observed that mRNA levels of ALP were over five fold increased at 14 days at concentrations of ten and $50 \mathrm{ng} / \mathrm{ml}$ rhBMP2_108 whereas at a concentration of 100 and $200 \mathrm{ng} / \mathrm{ml} 20$ fold increase in ALP activity (Fig. 4c). The highest concentration of $500 \mathrm{ng} / \mathrm{ml}$ demonstrated a 40 fold increase in ALP activity when compared to culture media without rhBMP2 (Fig. 4c). The greatest fold change

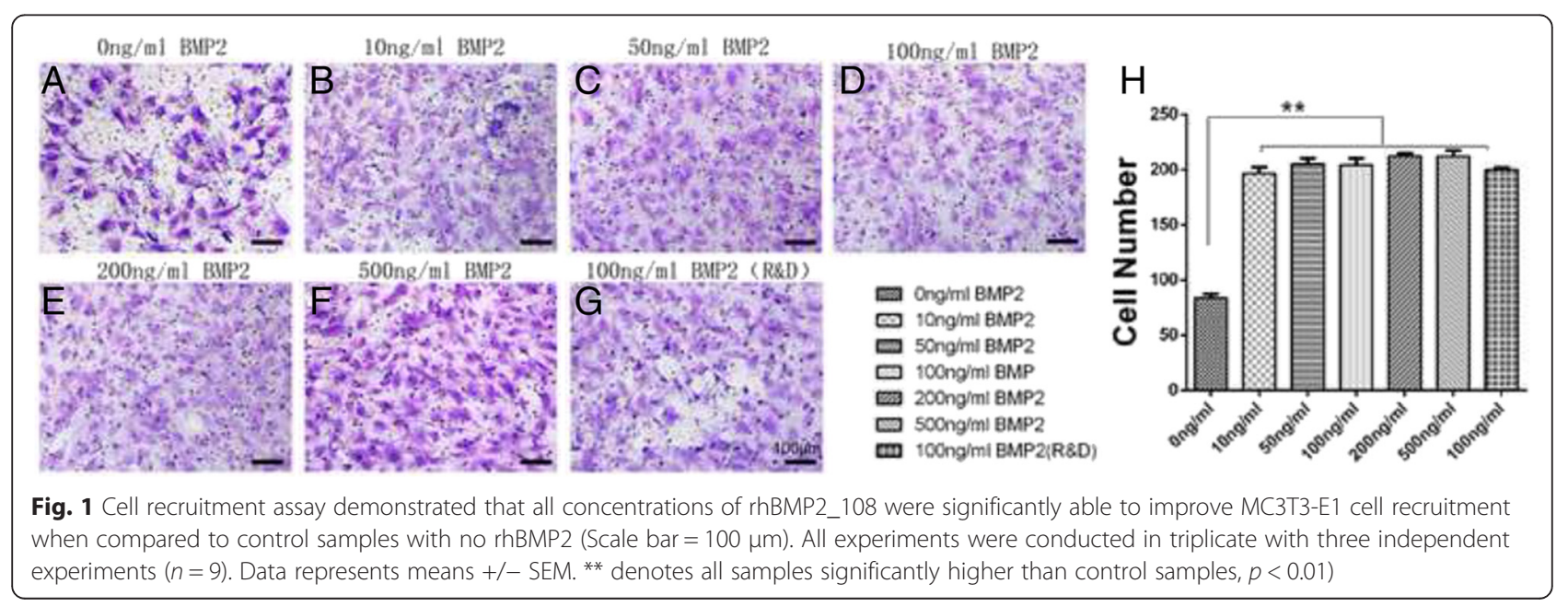




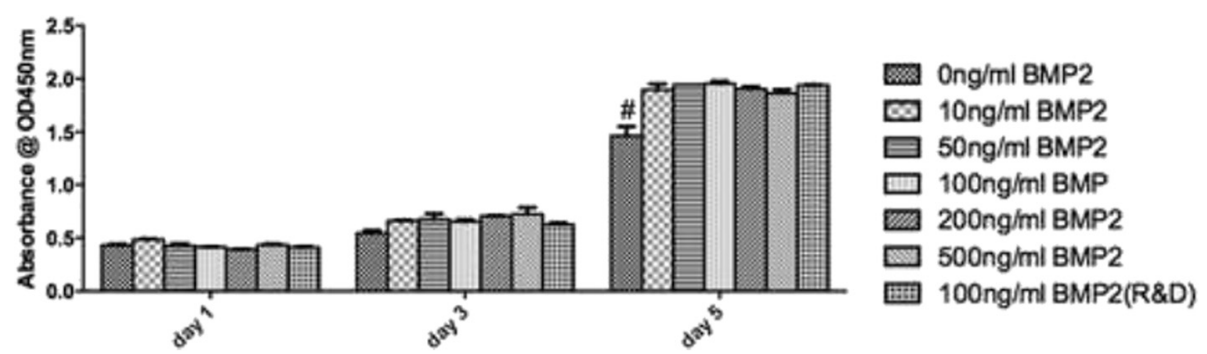

Fig. 2 Cell number as calculated by an CCK-8 assay for MC3T3-E1 cells seeded at various concentrations of rhBMP2_108 when compared to control tissue culture plastic (All experiments were conducted in triplicate with three independent experiments $(n=9)$. Data represents means $+/-$ SEM. \# denotes control samples significantly lower than all other treatment modalities, $p<0.05$ )

was observed in OCN levels where up to a 300 fold increase was observed when compared to their respective control without rhBMP2 (Fig. 4d).

Lastly, alizarin red staining was used to visualize in vitro mineralization (Fig. 5). It was observed that without
rhBMP2, MC3T3-E1 pre-osteoblasts were unable to generate any visual mineralization as observed by alizarin red staining (Fig. 5). The effects of rhBMP2_108 demonstrated a significant concentration dependent increase in alizarin red staining at 14 days post seeding (Fig. 6).
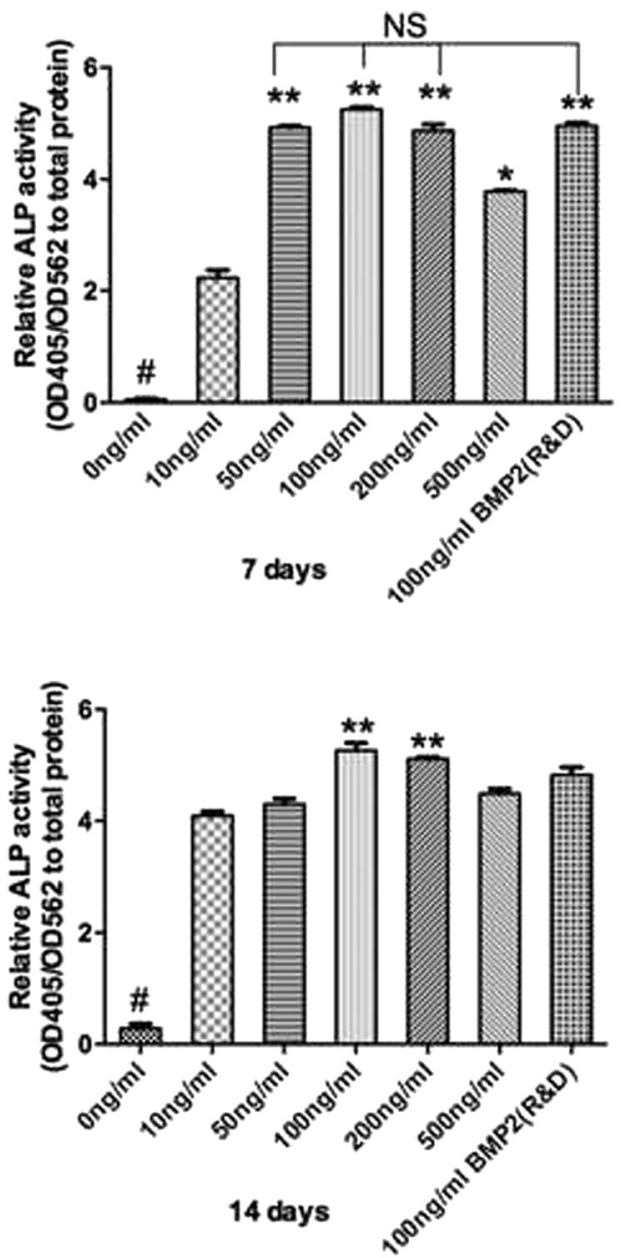

Ong/ml BMP2

10ng/ml BMP2

回 $50 \mathrm{ng} / \mathrm{ml}$ BMP2

$100 \mathrm{ng} / \mathrm{ml} \mathrm{BMP}$

200ng/ml BMP2

$500 \mathrm{ng} / \mathrm{ml} \mathrm{BMP2}$

四 100ng/ml BMP2(R\&D)

Fig. 3 ALP activity was significantly increased at seven and 14 days post seeding for samples seeded with rhBMP2_108 when compared to control tissue culture plastic alone (All experiments were conducted in triplicate with three independent experiments $(n=9)$. Data represents means $+/-$ SEM. * denotes significant difference between $500 \mathrm{ng} / \mathrm{ml}$ and $10 \mathrm{ng} / \mathrm{ml} \mathrm{rhBMP} 2, p<0.05$; ** denotes significantly higher than all other modalities, $p<0.05$, \# denotes control samples significantly lower than all other treatment modalities, $p<0.05$ ) 


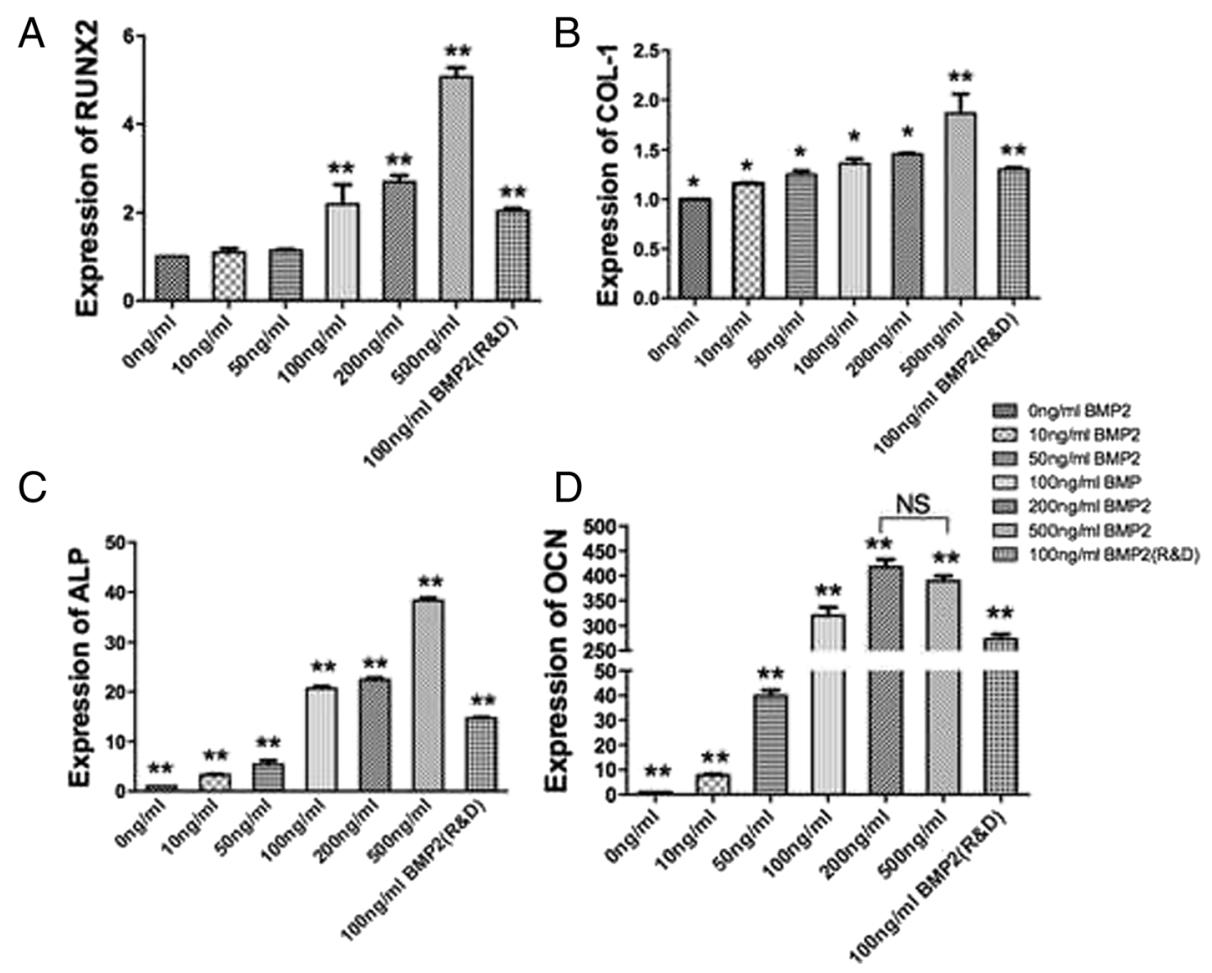

Fig. 4 mRNA levels of (a) ALP, (b) OCN, (c) COL-1 and (d) Runx2 for MC3T3-E1 cells seeded at various concentrations of rhBMP2_108 (All experiments were conducted in triplicate with three independent experiments $(n=9)$. Data represents means $+/-$ SEM. * denotes $p<0.05$; ** denotes significantly higher than all other modalities, $p<0.05$, \# denotes control samples significantly lower than all other treatment modalities, $p<0.05$ )

\section{Discussion}

The aim of the present study was to investigate the bioactivity of a shorter recombinant BMP2 (rhBMP2_108) sequence on osteoblast behavior. The use of rhBMP2 for orthopaedic and dental treatments has been utilised for a number of procedures including open fractures, hip reconstructive surgeries as well as guided bone regeneration procedures in dentistry [30-33]. Despite demonstrating promising in vivo results, growth factor use has had a mix of success when utilised for clinical use. Some of the key concerns raised with respect to growth factor utilisation is their transient bioactivity which has been suggested could to be in the order of minutes to hours [18].

There are three main areas of research aimed at improving the bioactivity of growth factors; 1 ) utilising gene therapy, 2) improving protein stability or 3 ) improving the growth factor delivery system. One method that has shown early promise for growth factor delivery is that of gene therapy where the use of viral vectors such as adenovirus may circumvent many of the limitations of protein delivery by exhibiting a high in vivo transduction efficiency with a relatively short expression period [34-38]. Their main advantage is the over-expressed protein is constructed within the organisms main cell and thus has access to a multitude of folding proteins capable of accurately packaging and delivering growth factors to their surrounding tissues $[25,39,40]$. Despite the advancements made in this area of research, the use of gene therapy is still prohibited by the FDA making its future clinical use at the moment a future optimistic approach with no known timetable for its eventual use. Furthermore, recent strategies utilizing short synthetic BMP2-mimicking

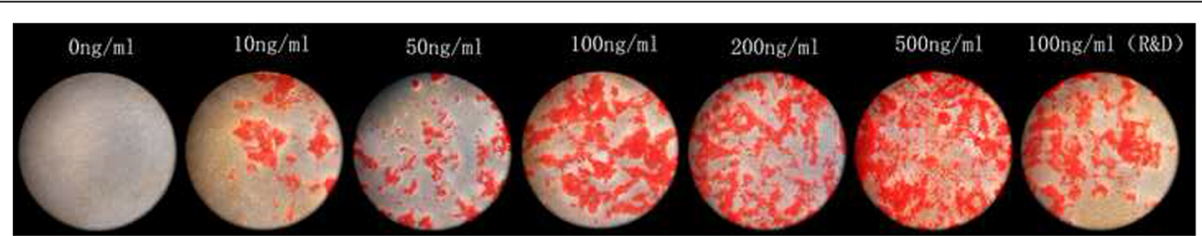

Fig. 5 Qualitative analysis of alizarin red staining demonstrated increased mineralization for MC3T3-E1 cells at increasing concentrations of rhBMP2_108 at 14 days post seeding 


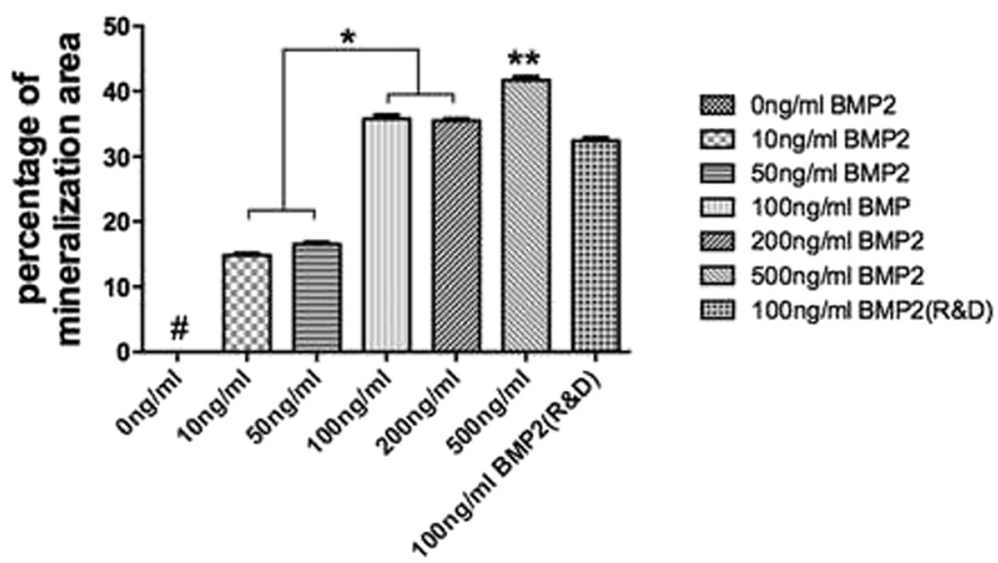

Fig. 6 Quantitative analysis of alizarin red staining. rhBMP2_108 demonstrate a concentration dependent increase in alizarin red staining (All experiments were conducted in triplicate with three independent experiments $(n=9)$. Data represents means $+/-\mathrm{SEM} .{ }^{*}$ denotes significant difference between two groups, $p<0.05$; ** denotes significantly higher than all other modalities, $p<0.05$, \# denotes control samples significantly lower than all other treatment modalities, $p<0.05$ )

peptides have been shown to facilitate bone regeneration [41-44], however a lack of clinical reports utilizing such strategies is still lacking.

Thus it becomes vital to find alternative methods that may be deemed suitable for improvements in growth factor bioactivity. In the present study, a novel recombinant version of BMP2 (rhBMP2_108) with a shorter amino acid sequence. Prior to animal testing however, in vitro testing was performed on cell activity. It was found in the present study that $\mathrm{r}$ rhBMP2_108 was firstly able to target the recruitment of progenitor cells by favouring early and rapid recruitment of cells within $24 \mathrm{~h}$ (Fig. 1). The homing of progenitor cells and stem cells is one of the key initial stages in the early onset of fracture repair and is a necessary component of wound healing of bony-defects. As such, the ability for rhBMP2_108 to speed up the rate and number of progenitor cells to defects sites is crucial for bone repair.

Although the effects as seen in the present study demonstrated that rhBMP2_108 was significantly able to induce cell proliferation, it was not observed in a concentration dependent manner. This can be due to the fact that cells undergoing cell differentiation are not prone to proliferate simultaneously. While not much concentration dependant observations were found for cell recruitment or proliferation, significant differences were found for osteoblast differentiation in response to rhBMP2_108. It was observed that over a four fold increase in ALP activity were detected with rhBMP2_108 and further concentration dependant increases in alizarin red staining further validated our hypothesis that rhBMP2_108 acts primarily by stimulating osteoblast differentiation. It was also observed that a significant increase in mRNA levels of ALP was observed in a concentration dependant manner.
Interestingly $\mathrm{OCN}$, a late differentiation marker for osteoblasts was upregulated approximately 300 fold when compared to control samples (Fig. 4b). This finding likely signifies that the MC3T3-E1 pre-osteoblasts seeded in control wells without rhBMP2 likely remained progenitor cells and did not differentiate towards the osteoblast lineage throughout the course of these experiments. This is further evident by the fact that the samples without rhBMP2 showed no mineralization potential in the alizarin red experiments (Fig. 5).

Although the results from the present study confirm the effects of this shorter amino acid sequence of rhBMP2_108 on cell activity, much research remains necessary in order to validate these findings in an animal model prior to clinical testing. It remains virtually unknown if the protein activity will be affected in vivo by the shortened amino acid sequence and much future research investigating this relationship both with respect to protein half-life duration as well as its subsequent effects on bone formation need to be carefully evaluated. Furthermore, its comparison to leading rhBMP2 currently available on the market with FDA approval is also necessary to provide a better understanding on the effects of protein amino acid length on bioactivity of recombinant proteins.

\section{Conclusion}

The results from the present study demonstrate that a shorter amino acid sequence of recombinant BMP2 (rhBMP2_108) retains bioactive properties of BMP2 when compared to commercially available rhBMP2 in vitro. It was shown that rhBMP2_108 was able to stimulate rapid cell recruitment of MC3T3-E1 pre-osteoblasts and support their differentiation towards the osteoblast lineage in 
a concentration dependant manner. Future in vivo research analyzing the use of this amino acid sequence of rhBMP2_108 is now necessary in critically-sized bone defects. Furthermore, investigation on the optimal delivery system this growth factor are necessary to potentially further improve its bioactivity for clinical use.

\begin{abstract}
Abbreviations
rhBMP2: recombinant bone morphogenetic protein 2; rhBMP2_108: Short polypetitde chain of 108 amino acids for recombinant bone morphogenetic proteins two; ALP: alkaline phosphatase; OCN: osteocalcin; COL-1: collagen 1; Runx2: runt-related transcription factor two; GAPDH: glyceraldehyde 3-phosphate dehydrogenase; FDA: food and drug administration; $\mathrm{CHO}$ : Chinese hamster ovary; PCR: polymerase chain reaction; PBS: phosphate buffered solution; $\mathrm{HCl}$ : hydrochloric acid; EDTA: ethylenediaminetetraacetic acid; NaCl: sodium chloride; DMEM: Dulbecco's modified eagle medium; BCA: bicinchoninic acid; OD: pptical density; SE: standard error.
\end{abstract}

\section{Competing interests}

rhBMP2_108 was kindly provided by Hangzhou Jluyuan Gene Engineering Co., Ltd (Hangzhou, China) where Hang Fu, Wei Zhou, Li Qian are presently employed. The authors report no other conflict of interest for this study.

\section{Authors' contributions}

YZ, YS, HF, WZ, LQ, JD and RJM have made substantial contributions to conception and design, YZ, YS and JD have done the acquisition of data, and $Y Z, Y S, J D$ and RJM have performed analysis and interpretation of data. $Y Z, H F, W Z, L Q$ and RJM have been involved in drafting the manuscript or revising it critically for important intellectual content. YZ, YS, HF, WZ, LQ, JD, RJM have given final approval of the version to be published.

\section{Acknowledgements}

This project was supported by Program for New Century Excellent Talents in University (NCET-11-0414), Excellent Youth Foundation of Hubei and the funds of the National Natural Science Foundation of China (81271108).

\section{Author details \\ ${ }^{1}$ The State Key Laboratory Breeding Base of Basic Science of Stomatology (Hubei-MOST) \& Key Laboratory of Oral Biomedicine Ministry of Education, School \& Hospital of Stomatology, Wuhan University, 237 Luoyu Road, Wuhan 430079, People's Republic of China. ${ }^{2}$ Department of Oral Implantology, School of Stomatology, Wuhan University, Wuhan 430079, China. ${ }^{3}$ Department of Oral Surgery and Stomatology, University of Bern, Freiburgstrasse 7, Bern 3010, Switzerland. ${ }^{4}$ Department of Periodontology, School of Dental Medicine, University of Bern, Freiburgstrasse 7, Bern 3010, Switzerland. ${ }^{5}$ Hangzhou Jluyuan Gene Engineering Co, Ltd;East of No.8 Street, Hangzhou Econ. and Tech. Development Zone, Hangzhou, China Hangzhou China 310018, China.}

Received: 17 August 2015 Accepted: 16 December 2015

Published online: 30 December 2015

\section{References}

1. Calori GM, Mazza E, Colombo M, Ripamonti C. The use of bone-graft substitutes in large bone defects: any specific needs? Injury. 2011;42 Suppl 2:S56-63.

2. Darby IB, Morris KH. A systematic review of the use of growth factors in human periodontal regeneration. J Periodontol. 2013;84(4):465-76.

3. Ramseier CA, Rasperini G, Batia S, Giannobile W. Advanced reconstructive technologies for periodontal tissue repair. Periodontol 2000. 2012;59(1):185-202.

4. Genant HK, Cooper C, Poor G, Reid I, Ehrlich G, Kanis J, et al. Interim report and recommendations of the world health organization task-force for osteoporosis. Osteoporos Int. 1999;10(4):259-64.

5. Roush K. Prevention and treatment of osteoporosis in postmenopausal women: a review. Am J Nurs. 2011;111(8):26-35. quiz 36-27.

6. Bernabei R, Martone AM, Ortolani E, Landi F, Marzetti E. Screening, diagnosis and treatment of osteoporosis: a brief review. Clinical cases in mineral and bone metabolism : the official J Ital Soc Osteoporos, Miner Metab,Skeletal Dis. 2014;11(3):201-7.

7. Rao SK, Rao AP. A literature review and case series of accelerating fracture healing in postmenopausal osteoporotic working women. J Orthop. 2014;11(3):150-2.
8. Moazzaz P, Gupta MC, Gilotra MM, Gilotra MN, Maitra S, Theerajunyaporn T, et al. Estrogen-dependent actions of bone morphogenetic protein-7 on spine fusion in rats. Spine (Phila Pa 1976). 2005;30(15):1706-11.

9. Hao YJ, Zhang G, Wang YS, Qin L, Hung WY, Leung K, et al. Changes of microstructure and mineralized tissue in the middle and late phase of osteoporotic fracture healing in rats. Bone. 2007:41(4):631-8.

10. Namkung-Matthai $H$, Appleyard R, Jansen J, Hao Lin J, Maastricht S, Swain M, et al. Osteoporosis influences the early period of fracture healing in a rat osteoporotic model. Bone. 2001;28(1):80-6.

11. Rodan GA, Martin TJ. Therapeutic approaches to bone diseases. Science. 2000:289(5484):1508-14

12. White AP, Vaccaro AR, Hall JA, Whang PG, Friel BC, McKee MD. Clinical applications of BMP-7/OP-1 in fractures, nonunions and spinal fusion. Int Orthop. 2007:31(6):735-41.

13. Govender S, Csimma C, Genant HK, Valentin-Opran A, Amit Y, Arbel R, et al. Recombinant human bone morphogenetic protein-2 for treatment of open tibial fractures: a prospective, controlled, randomized study of four hundred and fifty patients. J Bone Joint Surg Am. 2002;84-A(12):2123-34

14. Miron RJ, Zhang YF. Osteoinduction: A Review of Old Concepts with New Standards. J Dent Res. 2012;91(8):736-44.

15. Urist MR. Bone: formation by autoinduction. Science NY. 1965;150(698):893-9.

16. Urist MR, Strates BS. Bone morphogenetic protein. J Dent Res. 1971:50(6):1392-406.

17. Lissenberg-Thunnissen SN, de Gorter DJ, Sier CF, Schipper IB. Use and efficacy of bone morphogenetic proteins in fracture healing. Int Orthop. 2011;35(9):1271-80.

18. Anusaksathien $\mathrm{O}$, Giannobile WV. Growth factor delivery to re-engineer periodontal tissues. Curr Pharm Biotechnol. 2002;3(2):129-39.

19. Kannan A, Dodwad SN, Hsu WK. Biologics in spine arthrodesis. J Spinal Disord Tech. 2015:28(5):163-70.

20. Reddi AH. Interplay between bone morphogenetic proteins and cognate binding proteins in bone and cartilage development: noggin, chordin and DAN. Arthritis Res. 2001;3(1):1-5.

21. Demain AL, Vaishnav P. Production of recombinant proteins by microbes and higher organisms. Biotechnol Adv. 2009;27(3):297-306.

22. Zhou A, Clokie CML, Peel SAF. Enhancing production of recombinant BMP-2 in mammalian cell culture. FASEB J. 2009;23(1_MeetingAbstracts):LB209.

23. Baneyx F, Mujacic M. Recombinant protein folding and misfolding in Escherichia coli. Nat Biotechnol. 2004;22(11):1399-408.

24. Lee JH, Kim CS, Choi KH, Jung UW, Yun JH, Choi SH, et al. The induction of bone formation in rat calvarial defects and subcutaneous tissues by recombinant human BMP-2, produced in Escherichia coli. Biomaterials. 2010;31(13):3512-9.

25. Zhang Y, Ma Y, Wu C, Miron RJ, Cheng X: Platelet-derived growth factor BB gene-released scaffolds: biosynthesis and characterization. Journal of tissue engineering and regenerative medicine 2013. doi:10.1002/term.182.

26. Zhang Y, Wei L, Chang J, Miron RJ, Shi B, Yi S, et al. Strontium-incorporated mesoporous bioactive glass scaffolds stimulating in vitro proliferation and differentiation of bone marrow stromal cells and in vivo regeneration of osteoporotic bone defects. J Mater Chem B. 2013;1(41):5711-22.

27. Miron RJ, Hedbom E, Ruggiero S, Bosshardt DD, Zhang Y, Mauth C, et al. Premature osteoblast clustering by enamel matrix proteins induces osteoblast differentiation through up-regulation of connexin 43 and N-cadherin. PLoS One. 2011:6(8):e23375.

28. Zhang Y, Wei L, Miron RJ, Shi B, Bian Z. Anabolic bone formation via a site-specific bone-targeting delivery system by interfering with semaphorin $4 \mathrm{~d}$ expression. J bone and miner res: the official J AmSoc Bone Miner Res. 2015;30(2):286-96

29. Zhang Y, Wu C, Friis T, Xiao Y. The osteogenic properties of CaP/silk composite scaffolds. Biomaterials. 2010;31(10):2848-56.

30. Pimenta L, Marchi L, Oliveira L, Coutinho E, Amaral R. A prospective, randomized, controlled trial comparing radiographic and clinical outcomes between stand-alone lateral interbody lumbar fusion with either silicate calcium phosphate or rh-BMP2. J neurol surg Part A, Cen Eur Neurosurg 2013:74(6):343-50

31. Chang YY, Lee JS, Kim MS, Choi SH, Chai JK, Jung UW. Comparison of collagen membrane and bone substitute as a carrier for rhBMP-2 in lateral onlay graft. Clin Oral Implants Res. 2015;26(1):e13-19.

32. Shim JH, Yoon MC, Jeong CM, Jang J, Jeong SI, Cho DW, et al. Efficacy of rhBMP-2 loaded PCL/PLGA/beta-TCP guided bone regeneration membrane fabricated by 3D printing technology for reconstruction of calvaria defects in rabbit. Biomed Mater. 2014;9(6):065006. 
33. Wikesjo UM, Qahash M, Huang YH, Xiropaidis A, Polimeni G, Susin C. Bone morphogenetic proteins for periodontal and alveolar indications; biological observations - clinical implications. Orthod Craniofac Res. 2009;12(3):263-70.

34. Chang PC, Seol YJ, Cirelli JA, Pellegrini G, Jin Q, Franco LM, et al. PDGF-B gene therapy accelerates bone engineering and oral implant osseointegration. Gene Ther. 2010;17(1):95-104.

35. Fang J, Zhu YY, Smiley E, Bonadio J, Rouleau JP, Goldstein SA, et al. Stimulation of new bone formation by direct transfer of osteogenic plasmid genes. Proc Natl Acad Sci U S A. 1996;93(12):5753-8.

36. Ramseier CA, Abramson ZR, Jin Q, Giannobile WW. Gene therapeutics for periodontal regenerative medicine. Dent Clin North Am. 2006;50(2):245-63. ix.

37. Zhang Y, Wu C, Luo T, Li S, Cheng X, Miron RJ. Synthesis and inflammatory response of a novel silk fibroin scaffold containing BMP7 adenovirus for bone regeneration. Bone. 2012;51(4):704-13.

38. Zhang Y, Miron RJ, Li S, Shi B, Sculean A, Cheng X. Novel MesoPorous BioGlass/silk scaffold containing adPDGF-B and adBMP7 for the repair of periodontal defects in beagle dogs. J Clin Periodontol. 2015;42(3):262-71.

39. Ghosh SS, Gopinath P, Ramesh A. Adenoviral vectors: a promising tool for gene therapy. Appl Biochem Biotechnol. 2006;133(1):9-29.

40. Zhang Y, Cheng N, Miron R, Shi B, Cheng X. Delivery of PDGF-B and BMP-7 by mesoporous bioglass/silk fibrin scaffolds for the repair of osteoporotic defects. Biomaterials. 2012:33(28):6698-708.

41. Pan H, Hao S, Zheng Q, Li J, Zheng J, Hu Z, et al. Bone induction by biomimetic PLGA copolymer loaded with a novel synthetic RADA16-P24 peptide in vivo. Mater Sci Eng, C. 2013;33(6):3336-45.

42. Lin Z-Y, Duan Z-X, Guo X-D, Li J-F, Lu H-W, Zheng Q-X, et al. Bone induction by biomimetic PLGA-(PEG-ASP) $n$ copolymer loaded with a novel synthetic BMP-2-related peptide in vitro and in vivo. J Control Release. 2010;144(2):190-5.

43. Wu B, Zheng Q, Guo X, Wu Y, Wang Y, Cui F. Preparation and ectopic osteogenesis in vivo of scaffold based on mineralized recombinant human-like collagen loaded with synthetic BMP-2-derived peptide. Biomed Mater. 2008;3(4):044111.

44. Yuan Q, Lu H, Tang S, Liu K, Pan Z, Pan H, et al. Ectopic bone formation in vivo induced by a novel synthetic peptide derived from BMP-2 using porous collagen scaffolds. J Wuhan Univ Technol-Mater Sci Ed. 2007;22(4):701-5.

\section{Submit your next manuscript to BioMed Central and we will help you at every step:}

- We accept pre-submission inquiries

- Our selector tool helps you to find the most relevant journal

- We provide round the clock customer support

- Convenient online submission

- Thorough peer review

- Inclusion in PubMed and all major indexing services

- Maximum visibility for your research

Submit your manuscript at www.biomedcentral.com/submit

) Biomed Central 